\title{
Using Standards for Internal Quality Assurance for Management and Program Administration
}

\author{
Richmond Stroupe \\ Soka University, Japan \\ richmond@soka.ac.jp
}

\begin{abstract}
This paper considers how local, national, and international standards can be used as a guide for management, administrative, or program development. Beginning with background information regarding the use of standards for accreditation, suggestions on how such standards can be used for other "internal" purposes will be presented. The goal of the use of such standards is not solely on the final objective of accreditation, but rather on how all educational institutions can utilize such standards as tools in the ongoing process of improving educational quality assurance in management and program administration. Recommendations for educational leaders and institutions will include prioritizing the areas in their particular educational contexts in which to apply standards, reviewing and selectively utilizing relevant international, national or local standards, and maintaining transparency and ownership.
\end{abstract}

Increasingly, quality assurance issues are being emphasized by educational agencies and institutions in all contexts, including those in developing as well as developed countries, and across all levels, including primary, secondary and tertiary (Stroupe, 2009). In Cambodia, the newly formed Accreditation Committee of Cambodia (ACC) is charged with accrediting and ensuring the quality of institutions of higher education (Sithol, 2010). Standards and benchmarks for all levels of the educational system in Japan are maintained and enforced by the Ministry of Education, Culture, Sports, Science and Technology (MEXT) (Doyon, 2001; National Institute on Student Achievement, Curriculum, and Assessment, 1998; Teichler, 1997). In Australia, the Department of Education, Employment and Workplace Relations (DEEWR), along with territorial agencies, oversees educational programs and institutions (DEEWR, 2010), while the National ELT Accreditation Scheme (NEAS) develops standards for English language teaching (ELT) and provides accreditation for ELT institutions and programs (NEAS, 2010). American educators are familiar with the educational and institutional ramifications of the No Child Left Behind standards-based policies of the Bush administration in the United States, and resulting controversies (Balfanz, Legters, West, \& Weber, 2007; Burch, Steinberg, \& Donovan, 2007; Fuller, Wright, Gesicki, \& Kang, 2007). More recently, the Common Core Standards developed by the National Governors Association Center for Best Practices (NGA Center) and the Council of Chief State School Officers (CCSSO) (CCSSO, 2010; Common Core Standards Initiative, 2010) will have far-reaching effects in the American education sector. In Europe and in countries outside the region which have chosen to adopt it, the Common European Framework of Reference for Languages: Learning, Teaching, Assessment (CEFR) (Council of Europe, 2001) is increasingly being used to benchmark language learning. Additionally, individual institutions are regularly faced with accreditation requirements from a number of

Language Education in Asia, 2010, 1(1), 124-132. http://dx.doi.org/10.5746/LEiA/10/V1/A11/Stroupe 
local, national, and international agencies and government institutions. In many ways, standards used to ensure quality are globally very much an integrated aspect of educational systems.

\section{Using National and International Standards}

National or international standards can also be used as a source of internal quality assurance, separate from the requirement of local, national, or international authorities. As an internal tool for evaluation or self-audit, such standards, which are readily available, can be utilized very effectively both by individuals and institutions (Stroupe, 2009). However, when first considering standards, leaders may become quite overwhelmed at the assumed expectations some standards impose, the complexity with which they are written, or the lack of immediate relevance to the local context. Mishra (2006) suggests that institutions consider their own contexts first, by asking how quality is defined and what internal and external forces drive the search for quality. This paper suggests that internal forces, including educational leaders or an institution which encourages an environment which supports quality assurance, can make use of available standards in an informal manner in order to support educators and administrative and program management as leaders and institutions strive to improve and maintain the quality of educational services.

\section{The Competitive Education Marketplace and Standards in the Language Learning Context}

In recent decades, a shift in educational philosophy related to language learning has occurred in many contexts. English is no longer viewed as only a subject to be studied objectively, but rather as a skill-based subject. Students learn how to use the language in practical circumstances, including educational and professional situations. Along with this shift to a skills-based approach, performance standards are increasingly being used to evaluate students' success or achievement (Stroupe, 2007, 2009). Reaching performance standards, which are based on what students should know or how they should be able to perform after a course or educational program and which are measured on a continuum, is important: such results can be required of educational institutions by stakeholders or accreditation agencies, of scholarship applicants by donor agencies, of employees by potential employers, and more recently, of education institutions by prospective students. Educational leaders and institutions are being faced with increased global and local competition (Bolden, 2008) and requirements to meet state and local guidelines/requirements related to curriculum and assessment design, professional development of teachers, and accreditation/evaluation (Stroupe, 2009). This increasing emphasis on performance standards is contributing to this growth in competition and the development of internal and external requirements of institutions, but may also provide opportunities for those same institutions to highlight and promote their successful programs.

As students become increasingly mobile (more able to travel great distances, in many cases internationally, to attend educational programs) and sophisticated in their personal evaluations of educational institutions, quality assurance issues are becoming more important. Students now have access to a global network of educational institutions, all of which are more and more appealing to an international student population. Parents, students themselves, and other funding agencies (such as administrators of scholarship programs, philanthropic organizations, and development agencies) are becoming more knowledgeable about different educational opportunities, and are increasingly concerned about the quality and cost of educational experiences. Such stakeholders are better informed of their rights as "education consumers" and are likely to hold educational institutions accountable with regard to overall quality of programs and whether stated goals and objectives are met (Mishra, 2006). 
Institutions themselves have a vested interest in improving and / or maintaining quality: increased quality results in increased credibility as well as increased prestige and status to the institutions and their staff. In turn, increases in prestige and status can be utilized to attract higher quality student applicants and staff and to place graduates in more attractive positions after graduation (Mishra, 2006).

Quality in the education sector is most often associated with the classroom: how well are students learning, how qualified are teachers, and how well do teachers teach? However, in a competitive education market, the classroom is merely one of a number of variables which may influence the choice of students to enroll in one institution over another (Figure 1). Along with the quality of educational programs, the reputation and prestige of the institution play important roles. Such variables may also affect how potential consumers evaluate the cost or convenience (for example, distance that must be traveled to the institution) of the institution weighed against its reputation. Relevance of programs to the educational or learning goals (academic, professional, content-specific) of prospective students can determine whether these potential students will show interest in a particular program. The number of relevant programs available in a specific area may increase the competition among those programs as potential students must choose between a number of options. Of course, the reverse is also true: if only one program is available, less competition may be realized. Many students may be concerned about the intellectual challenge (or lack thereof) which programs at an institution will provide them, or the general overall atmosphere of the learning environment provided (Higher Education Policy Institute, 2009). Additionally, administrative support and (non-academic) student services (e.g. counseling services, online student support services) may also factor into their decision-making process (Bolden, 2008). Education consumers make decisions on where, how, and when to study based on these variables of price, availability, and relevance. The decision-making process and the variables on which it is based are not static, but constantly changing and interrelated (Higher Education Policy Institute, 2009). Institutions can increase their visibility and marketability by proactively ensuring the quality of their services and programs through internal procedures. Employing standards to proactively evaluate and improve curriculum, staff development, management procedures, and program administration and services will ensure the quality of each component and the overall functioning of the institution.

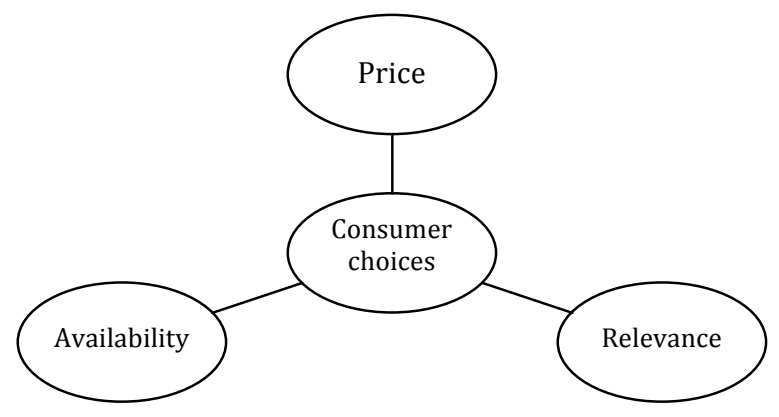

Figure 1. Interrelated variables affecting consumer choice in the education sector.

\section{What Standards are Related to Management and Program Administration?}

When associated with management and program administration, standards deal with the ability of an institution to provide or deliver services. Like performance standards, standards for management and program administration are also based on observable or quantifiable evidence that is used to show that the standards are being achieved (NEAS, 2010). 
Administrative and program standards can include the assessment of students, program design, and hiring and promotion practices (NEAS, 2010; Teachers of English to Speakers of Other Languages [TESOL], 2003). Additional examples are listed in Table 1.

\section{Table 1}

Management and Program Administration Standards Categories: Some Examples

Management and Administration

- Mission statement / philosophy

- Management structure

- Leadership and support staff / services

- Organizational goals

- Employment practices / conditions

- Professional development

- Instructor evaluation systems

- Channels of communication

- Linkages with stakeholders

- Confidentiality

- Quality assurance practices

- Student administration

- Learner recruitment, intake, orientation

- Planning systems

- Marketing

- Financial control
Program Delivery and Assessment

- Instructor qualifications / credentials

- Professional development

- Curriculum development

- $\quad$ Student / teacher ratio

- Timetables

- Teaching methodology / instruction

- Goals and objectives

- Program content

- Syllabus

- Equipment

- Resources

- Assessment procedures

- Course evaluation

Note. From National ELT Accreditation Scheme (NEAS). (2010). Standards and criteria for ELT Centres - International, retrieved from http://www.neas.org.au/international/ standards.php and Teachers of English to Speakers of Other Languages (TESOL). (2003). Standards for adult education ESL programs. Alexandria, VA.: TESOL Organization.

One organization which specifically targets international institutions (i.e., institutions outside of Australia) is the National ELT Accreditation Scheme (NEAS). This organization's standards for use in their accreditation process, Standards and Criteria for ELT Centres - International (NEAS, 2010), are available online (http://www.neas.org.au/international/standards.php). These standards have been developed based on consideration of the realities and constraints on institutions in the international context. They are also clear and concise, and therefore more accessible than other more complex and legalistic standards available through other agencies. In addition, the NEAS standards have a number of categories related directly to management and program administration.

\section{How Can Leaders Positively Influence Management and Program Quality?}

Quality assurance issues challenge all institutions, regardless of the level of development of the particular country where an institution is located or the type of students to which an institution caters. Each institution must address the cultural, traditional, administrative, and employee barriers in its context which must be overcome or addressed when quality assurance issues are presented or when standards are implemented. In some cases, institutions or educational leaders only consider quality issues or standards when it is time for the annual accreditation review. While accreditation is a potential and valuable result, it is not an absolutely necessary impetus. Striving for quality assurance is a process that can be started at any time and can be continued with leadership and support (NEAS, 2010; Stroupe, 2009; Tatton, 2010). Educational leaders in institutions play a key role in this process. Bryman (2009) reports that one of the three top qualities of successful leaders in education is the ability to promote excellence in teaching and learning in a department or program. However, at the same time, Bryman (2009) 
points out that leaders can overload teachers, thereby lessening the chances that educational reform, including improvements in quality assurance, will be successful. In fact, inappropriate implementation of quality assurance systems can result in a reduction in the development of innovative approaches to the delivery of educational services.

Each educational institution exists in a unique context, with accompanying restrictions and limitations on resources and flexibility of operations. As a result, each educational leader should question what type of quality assurance measures is feasible. Appendix A presents a number of features of quality assurance systems; however, leaders must consider which are most relevant to their educational contexts. In addition, most institutions cannot address all aspects of the administrative and program management at once, but must prioritize based on where the greatest need may exist, and where the most beneficial impact could be realized. Appendix B lists a number of reflective questions for educational leaders when considering the quality assurance process. The challenge for educational leaders is to find the balance: determine what is feasible at a particular time and encourage quality, while taking care to avoid stifling innovation and creativity at the same time. This is a global issue that all educational leaders face (Leadership Foundation for Higher Education, 2006). The key to quality assurance is to start the process. Quality assurance is a system: Starting at one point within the system will lead to advantageous changes in other parts of the system. One must start somewhere.

\section{Recommendations on How to Start and Continue the Quality Assurance Process}

Below are a number of steps which educational leaders and other educators can take in order to utilize standards as a tool to improve quality within institutional management and program administration:

Consider the context. As mentioned above, each educational context is unique, and each institution faces complex and varying internal and external challenges. Working with colleagues to identify potential areas for improvement is an effective initial step.

Expand ownership of the process. It is important that members of administrative units, including staff, managers, teachers, and other educational leaders feel that they are not only a part of the process, but that their views, recommendations, and objections are taken seriously and respected. Negotiating the emphasis, priorities, and features of the quality assurance system is important. This process may be time consuming, but will lead to a higher likelihood of success in the long run. Introducing the quality assurance system, establishing channels of communication for input from all interested parties, ensuring transparency, maintaining representation on committees of diverse stakeholders from all levels of the organization, and negotiating procedures with all involved is a lengthy but valuable process in which the institution as a whole can and should engage.

Consider feasibility. What really is possible given the situation of the institution? Consider available resources, the employment market, government policies, physical limitations, and competition from other educational institutions.

Prioritize the institution's needs. Where is change most needed? In most cases, it is not possible nor is it wise for institutions to address quality issues in all areas of management and program administration at once. In each institution, based on the input from all stakeholders, areas where the need is greatest, where change is feasible, and where the most benefit can be realized can be prioritized. 
Consider available standards. Standards are widely available in the public domain. Many organizations produce standards, local and national governments implement standards, and a number of agencies provide standards for use in their accreditation processes. In most cases, once accessing these standards, it will be necessary to adapt individual standards, adopt others, and disregard still others based on the realities of the context of each educational institution.

For example, in the case of the development of the program content of a Master's degree program in TESOL at the Japanese university where the author is a faculty member, the TESOL/NCATE accreditation standards from the United States for English as a Second Language (ESL) P-12 (preschool through grade 12) Teacher Education Programs were used. Without specific curriculum guidelines, performance benchmarks, or quality standards in the Japanese context for such a program, these standards from another country were utilized to evaluate the curriculum during the development stage. In some cases, the standards, such as demonstrating knowledge of syntax, World Englishes, or phonology, could be used in their entirety. However, others, such as understanding the history and current situation of immigration in the United States, were deemed irrelevant for our purposes. For ESL teachers in the United States, knowledge of immigration issues is increasingly important; for English as a Foreign Language (EFL) teachers in Japan, this knowledge is not necessary. In all, more than $95 \%$ of the approximately 70 standards for teacher education programs in the United States were relevant to our program in Japan. Although many had to be adapted, this set of standards allowed us to evaluate our program in an objective manner and led to informed decisions regarding curriculum changes that were to be made during the development process.

Consider the process, not just the product. Ensuring quality is a process that takes time. In a situation where an institution utilizes standards for internal purposes, the product may not be eventual accreditation. Rather, the process itself is what is important. Every institution should be implementing quality assurance practices. The use of available standards is one tool that can focus the quality assurance process and be used in self-evaluation for both institutions and the administrative and teaching staff involved. The use of standards can objectify the process of improving and/or maintaining quality, allowing all involved to address their concerns against an independent standard.

Ensure continuing ownership. Ensuring ownership by all members of stakeholder groups continues throughout a successful quality assurance process. Maintaining channels of communication, transparency, and respect are all important and will ensure that all members of the institution will "remain at the table" and continue to contribute effectively.

The key is to start the process. Regardless of the restraints educational institutions must function under, all institutions can implement quality assurance procedures. Institutions that stand still in regard to quality will quickly become obsolete in an increasingly competitive global education market. As institutions progress through the quality assurance process, there will be difficulties and challenges, but the only wrong decision that may be made is to not start the process at all.

\section{Conclusion}

Globally, educational institutions are facing increasing competition from not only local but also international sources. Students, parents, and funding agencies are becoming more sophisticated in their ability to distinguish among the educational offerings available, and will make decisions regarding educational programs based on relevancy, availability, cost, and quality. Institutions engaged in effective quality assurance practices can provide themselves with a comparative advantage in this competitive education market. Making use of national or 
international standards is an opportunity for institutions to bring objectivity to the selfevaluation process. While special consideration should be given to adapting standards to the context of each educational institution, available standards remain a useful tool for educational leaders and educators in the process of ensuring quality in not only classroom activities, but also in administrative and program management practices. Educational leaders play an important role in ensuring the transparency of quality assurance practices, maintaining ownership among stakeholders, balancing the implementation of quality assurance systems, and ensuring flexibility to be responsive to changes in the field and the market as competition and the growth of an informed student population continue to increase. The quality assurance process should be viewed in a long-term perspective. And while there will be challenges throughout this process, the only misstep an institution may make is not to start the process at all.

\section{Biodata}

Richmond Stroupe has worked with university and professional language learners since 1989. $\mathrm{He}$ is Chair of the Master's Program in International Language Education: TESOL at Soka University, Japan, and Chair of the Standing Committee on Standards with TESOL. His research interests include curriculum and professional development, and international comparative education.

\section{References}

Balfanz, R., Legters, N., West, T., \& Weber, L. (2007). Are NCLB's measures, incentives, and improvement strategies the right ones for the nation's low-performing high schools? American Educational Research Journal, 44(3), 559-593. http://dx.doi.org/10.3102/0002831207306768

Bolden, R. (2008). Research and development series: Developing collective leadership in higher education - Final report. Retrieved from http://www.Ifhe.ac.uk/

Bryman, A. (2009). Research and development series: Effective leadership in higher education Final report. Retrieved from http://www.Ifhe.ac.uk/

Burch, P., Steinberg, M., \& Donovan, J. (2007). Supplemental educational services and NCLB: Policy assumptions, market practices, emerging issues. Educational Evaluation and Policy Analysis, 29(2), 115-133. http://dx.doi.org/10.3102/0162373707302035

Common Core Standards Initiative. (2010). Common core state standards initiative (CCSSI). Retrieved from http://www.corestandards.org/

Council of Chief State School Officers (CCSSO). (2010). Council of Chief State School Officers (CCSSO). Retrieved from http://www.ccsso.org/

Council of Europe. (2001). Common European framework of reference for languages: Learning, teaching, assessment (CEFR). Retrieved from http://www.coe.int/T/DG4/Linguistic/CADRE_EN.asp

Department of Education, Employment and Workplace Relations (DEEWR). (2010). Australian Government: Department of Education, Employment and Workplace Relations. Retrieved from http://www.deewr.gov.au/Pages/default.aspx

Doyon, P. (2001). A review of higher education reform in modern Japan. Higher Education, 41(4), 443-470. http://dx.doi.org/10.1023/A:1017502308832

Fuller, B., Wright, J., Gesicki, K., \& Kang, E. (2007). Gauging growth: How to judge No Child Left Behind? Educational Researcher, 36(5), 268-278. http://dx.doi.org/10.3102/0013189X07306556

Higher Education Policy Institute. (2009). The role of the market in higher education. Retrieved from http://www.lfhe.ac.uk/ 
Leadership Foundation for Higher Education. (2006). The leadership and development challenges of globalization and internationalisation - Post Summit Report 2006. Retrieved from http://www.Ifhe.ac.uk/

Leadership Foundation for Higher Education. (2010). Leadership Foundation for Higher Education. Retrieved from http://www.Ifhe.ac.uk/

Mishra, S. (2006). Quality assurance in higher education: An introduction. Bangalore, India: National Assessment and Accreditation Council.

National ELT Accreditation Scheme (NEAS). (2010). Standards and criteria for ELT centres International. Retrieved from http://www.neas.org.au/international/ standards.php

National Institute on Student Achievement, Curriculum, and Assessment. (1998). The educational system in Japan: Case study findings. Retrieved from http://www2.ed.gov/pubs/JapanCaseStudy/index.html

Sithol, P. (2010, February). Quality assurance in higher education in Cambodia. Paper presented at the 6th CamTESOL Conference on English Language Teaching "One World: World Englishes," Phnom Penh, Cambodia.

Stroupe, R. (2007, January). Accountability for university ESL programs. Paper presented at the Thailand TESOL / 10th Pan-Asian Consortium International Conference "Beyond Boundaries: Teaching English for Global Communication in Asia," Bangkok, Thailand.

Stroupe, R. (2009, February). Practical application of language learning and teaching standards. Paper presented at the 5th CamTESOL Conference on English Language Teaching "The Globalization of ELT: Emerging Directions," Phnom Penh, Cambodia.

Tatton, S. (2010, February). Achieving and maintaining quality: Practical examples. Paper presented at the CamTESOL - 2010 Quality Assurance Forum, Phnom Penh, Cambodia.

Teachers of English to Speakers of Other Languages (TESOL). (2003). Standards for adult education ESL programs. Alexandria, VA: TESOL Organization.

Teichler, U. (1997). Higher education in Japan: A view from outside. Higher Education, 34(2), 275-298. http://dx.doi.org/10.1023/A:1003032909075 


\section{Appendix A \\ Academic Quality Management}

(Leadership Foundation for Higher Education, 2010)

Academic quality assurance and enhancement arrangements in institutions usually contain the following features:

- A quality policy or framework which sets out guidelines, regulations, and responsibilities for managing quality and safeguarding academic standards. This policy will be published and available to all staff, governors, and students.

- A charter or equivalent that sets out the expectations and responsibilities of students and the standards of care and service that they can expect from the institution and its staff.

- A cycle of validations and accreditation for new programs of study and reviews of existing programs.

- Systems for recruiting, training, and reviewing staff and their performance.

- Systems and procedures for assessing and examining student attainment, including the recruitment of external examiners.

- Systems for seeking, reviewing, and acting upon feedback from students and other stakeholders.

- Performance targets and indicators in key areas (e.g. student recruitment, retention, and attainment).

- A program to support quality improvement and development, building on key indicators and regular self-assessment.

- A system for monitoring success (in relation to quality and standards), for undertaking systematic reviews and for resolving problems.

\section{Appendix B \\ Quality: Key Questions [for Education Leaders]}

(Leadership Foundation for Higher Education, 2010)

In carrying out their strategic responsibilities in relation to quality, [leaders] may need to address a number of key questions:

- What is our institution's quality policy?

- What use does the institution make of external benchmarks?

- How does quality and how do standards of attainment match up with those of competitors and partners (as judged by performance and statistical indicators such as quality judgments, degree results, and employability indicators)?

- What are the outcomes of accreditation and review processes?

- How do particular groups of students perform, and how does this relate to key strategic areas?

- How is quality enhanced and how are academic standards maintained or raised?

- Are reports on quality matters regularly reported to governors? 